\title{
Assessing the potential of the rust fungus Puccinia spegazzinii as a classical biological control agent for the invasive weed Mikania micrantha in Papua New Guinea
}

\author{
M.D. Day ${ }^{\mathrm{a}, *}$, A.P. Kawi ${ }^{\mathrm{b}}$, C.A. Ellison ${ }^{\mathrm{c}}$ \\ a Department of Agriculture, Fisheries and Forestry, Biosecurity Queensland, Ecosciences Precinct, GPO Box 267, Brisbane, Qld 4001, Australia \\ ${ }^{\mathrm{b}}$ National Agricultural Research Institute, Islands Regional Centre, P.O. Box 204, Kokopo, East New Britain, Papua New Guinea \\ 'CABI Europe-UK, Bakeham Lane, Egham, Surrey TW20 9TY, United Kingdom
}

\section{H I G H L I G H T S}

- M. micrantha in different countries has different susceptibilities to P. spegazzinii.

- The host specificity of $P$. spegazzinii is confirmed.

- P. spegazzinii has the potential to reduce populations of $M$. micrantha.

\section{A R T I C L E I N F O}

\section{Article history:}

Received 29 May 2013

Accepted 6 August 2013

Available online 21 August 2013

\section{Keywords:}

Pathotype

Pathogenicity testing

Host specificity

Comparative growth studies
G R A P H I C A L A B S T R A C T

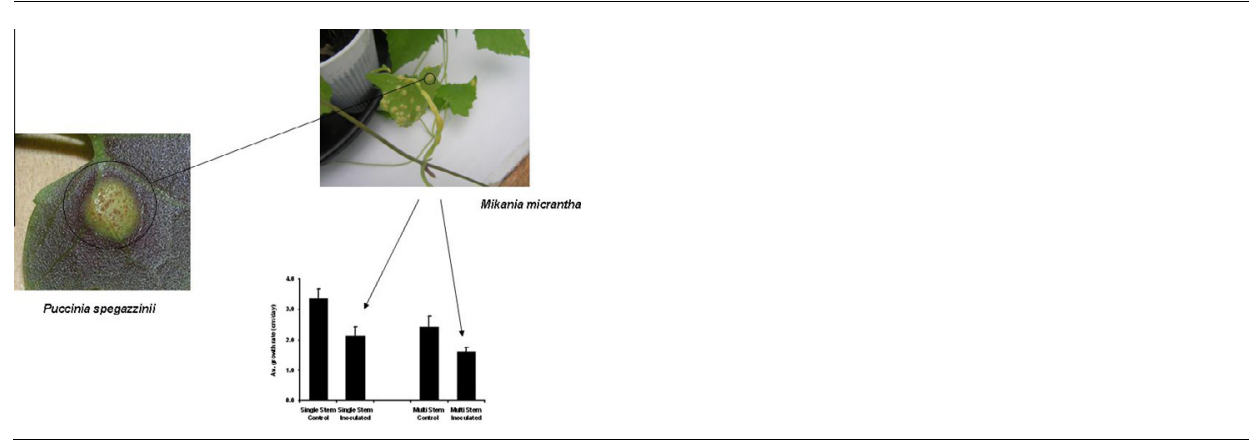

A B S T R A C T

The rust fungus Puccinia spegazzinii was introduced into Papua New Guinea (PNG) in 2008 as a classical biological control agent of the invasive weed Mikania micrantha (Asteraceae), following its earlier release in India, mainland China and Taiwan. Prior to implementing field releases in PNG, assessments were conducted to determine the most suitable rust pathotype for the country, potential for damage to non-target species, most efficient culturing method and potential impact to M. micrantha. The pathotype from eastern Ecuador was selected from the seven pathotypes tested, since all the plant populations evaluated from PNG were highly susceptible to it. None of the 11 plant species (representing eight families) tested to confirm host specificity showed symptoms of infection, supporting previous host range determination. A method of mass-producing inoculum of the rust fungus, using a simple technology which can be readily replicated in other countries, was developed. Comparative growth trials over one rust generation showed that M. micrantha plants infected with the rust generally had both lower growth rates and lower final dry weights, and produced fewer nodes than uninfected plants. There were significant correlations between the number of pustules and (a) the growth rate, (b) number of new nodes and (c) final total dry weight of single-stemmed plants placed in open sunlight and between the number of pustules and number of new nodes of multi-stemmed plants placed under cocoa trees. The trials suggest that field densities of $M$. micrantha could be reduced if the rust populations are sufficiently high.

Crown Copyright @ 2013 Published by Elsevier Inc. All rights reserved.

\footnotetext{
* Corresponding author.

E-mail addresses: Michael.Day@daff.qld.gov.au (M.D. Day), anna.kawi@nari.org.pg (A.P. Kawi), c.ellison@cabi.org (C.A. Ellison).
} 


\section{Introduction}

Mikania micrantha Kunth (Asteraceae), or mile-a-minute, is a fast growing, perennial vine native to the Neotropics. It is a major invasive weed in many countries of Southeast Asia, where it was introduced as a cover crop (Wirjahardja, 1976; Waterhouse, 1994). M. micrantha is also present in the Pacific, where it is found in 18 countries and territories, including Papua New Guinea (PNG) ${ }^{1}$ (Waterhouse and Norris, 1987; PIER - Pacific Island Ecosystems at Risk., 2012), affecting plantations and subsistence farms in areas up to an altitude of $1100 \mathrm{~m}$ above sea level (Waterhouse and Norris, 1987; Day et al., 2012). It flowers prolifically and the seeds are dispersed by wind or by people, becoming attached to clothing or possessions, and domestic animals (Holm et al., 1991; PIER - Pacific Island Ecosystems at Risk., 2012). In PNG, M. micrantha can grow about $4 \mathrm{~cm}$ /day and can form dense mats, smothering and killing crops such as banana, taro, papaw and young cocoa trees, thereby potentially reducing food security (Day et al., 2011).

Although some commercial plantations use herbicides, most control of M. micrantha in PNG is achieved through hand-pulling and slashing (Day et al., 2012). However, such methods are labour-intensive and unsustainable for small subsistence farmers, as plants quickly regrow from stem fragments (Holm et al., 1991; Day et al., 2012). Chemical control is not feasible for many subsistence farmers due to its high cost relative to the small scale of production and low income generated (Waterhouse and Norris, 1987; Orapa et al., 2001; Day et al., 2012). Therefore, biological control is seen as the only viable option to control this aggressive weed in most parts of PNG.

Biocontrol of $M$. micrantha first began in 1978, with exploration by CABI Europe-UK (CABI) in tropical America for potential agents, resulting in the introduction of Liothrips mikaniae (Priesner) (Thysanoptera: Phlaeothripidae) into the Solomon Islands in 1988 and Malaysia in 1990. However, this insect failed to establish in either country. It was also imported into PNG in 1989, but died out in quarantine before any field releases could occur (Cock et al., 2000).

In 1996, CABI surveyed tropical America for potential fungal pathogens for the control of $M$. micrantha in India, under a project funded by the UK-Department for International Development. Of several fungi found, the autoecious microcyclic rust fungus Puccinia spegazzinii de Toni (Pucciniales) was thought to be particularly damaging, as it attacks stems, petioles and leaves. Studies by CABI found that the strains of $P$. spegazzinii differed in their aggressiveness towards $M$. micrantha populations found in various invaded countries (Ellison et al., 2004). Host-specificity testing on 115 different plant species found the rust to be highly specific within the genus Mikania (Ellison et al., 2008). Different strains of the rust were subsequently released in India (2005), mainland China (2006) and Taiwan (2008), but the rust established only in Taiwan. However, in India and mainland China, the rust was released at very few sites, which may explain why it has apparently failed to establish (Ellison and Day, 2011).

In 2006, a new project on the biocontrol of M. micrantha commenced in PNG and Fiji, funded by the Australian Government and managed by the Queensland Government. The project aimed to introduce host-specific biocontrol agents that had been utilised elsewhere. The butterflies Actinote anteas (Doubleday and Hewitson) and $A$. thalia pyrrha Fabr. (Lepidoptera: Nymphalidae), which were reported damaging $M$. micrantha in Indonesia (Desmier de Chenon et al., 2002) (R. Desmier de Chenon Indonesian Oil Palm Research Institute pers. comm., 2006), and the rust P. spegazzinii,

\footnotetext{
1 Abbreviations used: PNG, Papua New Guinea, SSI, single stem inoculated; SSC, single stem control; MSI, multi-stem inoculated, MSC, multi-stem control.
}

were prioritized. This paper reports the pathogenicity and host-specificity testing conducted by CABI on behalf of PNG and the culturing and potential impact of the rust on M. micrantha in PNG.

\section{Materials and methods}

\subsection{Rust pathotype selection}

Seven isolates of $P$. spegazzinii, from Argentina, Brazil, Costa Rica, eastern and western Ecuador, Peru and Trinidad and Tobago, were assessed in isolation under quarantine conditions at CABI in the United Kingdom for their pathogenicity towards 10 accessions of M. micrantha from PNG and Fiji. Since the isolates varied in their pathogenicity towards genotypes within the species M. micrantha, they are referred to as pathotypes sensu lato (Ellison et al., 2004). Full details of the collection sites of the rust pathotypes and the method of shipment to the UK on living plants, are given in Evans and Ellison (2005). This involved collecting 3-4 recently infected plantlets (rooted nodes of runners), originating from the same plant, with pre-erumpent rust telia (5-10 per plantlet), at each site. A culture of each pathotype using all field material of that pathotype was then maintained separately to avoid cross-contamination with other pathotypes under quarantine (Ellison et al., 2008). Each pathotype was deposited as dried material in CABI Fungal herbarium (Herb. IMI).

M. micrantha plants were grown in a proprietary compost, maintained in an air-conditioned quarantine glasshouse, with supplementary lighting and a daily temperature range of $20-35^{\circ} \mathrm{C}$. The rust inoculation and assessment procedures were the same as those used in Ellison et al. (2008). Plant pieces (stems, petioles and leaves) containing the embedded teliospores of one of the pathotypes were suspended (by placing on a wire grid or attaching to a plant support frame with wire plant ties) over at least four young, healthy M. micrantha plants from each of the 10 accessions pruned to maximise the amount of meristematic tissue in a dew chamber (Mercia Scientific, Birmingham, UK) at $20^{\circ} \mathrm{C}$ for $24 \mathrm{~h}$ to encourage basidiospore formation, release and plant infection. The test was conducted for each of the seven rust pathotypes, using four fresh plants of each accession each time. The complete test of all rust pathotypes was repeated at least once, using fresh plants of each accession each time.

Rust isolates were rated for aggressiveness and ability to fully attack the 10 accessions of M. micrantha. Test plants were examined daily for symptom development. After 21 days, which is the average time required for full symptom development on a susceptible host (Ellison et al., 2008), plants were given a score using the scale below:

\section{No macroscopic symptoms.}

2. Necrotic or chlorotic spots on inoculated leaves - no sporulation.

3. Abnormal infection site: chlorotic patches on leaves with very low teliospore production around edges of chlorosis. No infection of petioles and stems.

4. Abnormal infection site: pustules reduced in size ( $<4 \mathrm{~mm}$ diameter) or with low teliospore production in relation to compatible host-pathogen interaction; on leaves petioles and stems.

5. Fully compatible host-pathogen interaction. Normal pustule formation (4-7 mm diameter - often coalescing) on leaves, petioles and stems.

As well as a numerical value, a '-' or '+' after the score was used, to indicate that a result is 'just in' or 'better', respectively, than the allocated numerical value. This was recorded to help with the selection of the optimum pathotype for introduction into PNG. 


\subsection{Host-specificity screening}

The pathotype of the rust (IMI 393075, eastern Ecuador), which had been selected for release in PNG and Fiji on the basis of the pathogenicity results, was extensively screened against 115 plant species in 45 families before being released in Taiwan in 2008 (S.S. Tzean, National Taiwan University, pers. comm.). Therefore, only 11 additional plant species of importance to the South Pacific or within the same family as M. micrantha, representing eight families, were tested on behalf of countries in the South Pacific: Bidens pilosa L., Zinnia sp., Hippobroma longiflora (L.) G. Don f., Scaevola sericea Vahl., Colocasia esculanta (L.) Schott, Anisomeles indica (L.) Kuntze, Hyptis pectinata (L.) Poit., Plectranthus scutellarioides (L.) R. Br., Psidium guajava L., Piper methysticum Foster f. and Morinda citrofolia L. (full details given in Table 2, Supplementary Material).

Host specificity was determined using the same inoculation procedure summarized above under 'Rust pathotype selection', with four plants of each of the eleven species tested at the same time against the eastern Ecuador pathotype. The complete test of all 11 species was repeated once, using four fresh plants of each species. All inoculations included a known, fully-susceptible $M$. micrantha plant as a control. Inoculated plants were observed daily for the development of symptoms, and all test plants were monitored for six weeks, which is twice the time required for full symptom development on M. micrantha (Ellison et al., 2008).

Due to the inoculation method, involving release of basidiospores, it is difficult to accurately quantify the amount of inoculum that a plant will receive in each experiment. However, the technique used (checking inoculum viability and position above test plant meristem, replication, repeat runs and control plants) ensures the results are scientifically robust.

\subsection{Culturing techniques and pathogen development in PNG}

Following approval by authorities in PNG to allow the rust to be released in the field, four small, bare-rooted $M$. micrantha plants of Fijian origin, inoculated with $P$. spegazzinii (IMI 393075) seven days previously, were imported under permit from the quarantine containment at CABI-UK into an air-conditioned post-entry quarantine laboratory $\left(26 \pm 1^{\circ} \mathrm{C}\right)$, with natural lighting at the National Agricultural Research Institute's (NARI) Islands Regional Centre (IRC) at Kerevat, East New Britain Province, PNG in November 2008. The plants were transplanted into four pots $(200 \mathrm{~mm}$ diameter by $180 \mathrm{~mm}$ high), filled with steam-sterilized topsoil mixture and placed in a sealed inoculation chamber made from clear Perspex $(600 \times 300 \times 600 \mathrm{~mm}$ high $)$ to aid recovery and allow the development of the rust pustules.

When the first pustules on the imported plants showed signs of maturing (approximately seven days after receiving the plants), as evidenced by a change in colour from bright yellow to golden brown, the plants were placed on a wire mesh stand in the inoculation chamber. Three or four fresh clean M. micrantha plants sourced from PNG in pots ( $200 \mathrm{~mm}$ diameter by $180 \mathrm{~mm}$ high) were placed directly below the infected plants, to maximise the chance of basidiospores landing on the fresh plants.

The humidity in the chamber was raised to $100 \%$ by spraying the uninfected plants with a fine layer of distilled water. This spraying facilitated basidiospore production from the teliospores on the infected plants, and provided the necessary conditions for infection of the fresh plants (i.e. through the provision of free water on the leaves). The infected plants were kept in the chamber for seven days, as the teliospores in the pustules develop sequentially, and this allowed time for younger teliospores to mature and germinate. Each day, a new batch of 3 or 4 fresh clean plants of PNG origin was added to the chamber and the previous batch removed, thus providing a 24-h period for infection of each batch of plants.
Over the seven days the original infected plants were in the chamber, 23 new plants were inoculated. These plants, of PNG origin, were later released from quarantine.

Inoculated plants removed from the chamber each day were held on a bench in the quarantine laboratory under a light bank, with 10-h light/14-h dark cycle, supplementing natural light for two days. The plants were then transferred to the quarantine screenhouse, with ambient temperature (ranging $28-40{ }^{\circ} \mathrm{C}$ ) and hand-watered when required. Once pustule development was evident on the new plants, the original imported plants were burnt. Further inoculations of fresh clean plants continued as above, as pustules on inoculated plants matured, to maintain a rust culture in PNG to facilitate field-releases.

Through daily observations of $M$. micrantha following inoculation, the life cycle and the duration of each stage of the developing pustules were determined. Descriptions and size of the pustules of each stage were recorded and compared with previous studies (Ellison et al., 2008).

To determine the optimum method for culturing P. spegazzinii under PNG conditions for field releases, seven culturing techniques were investigated (full details of each culturing method is presented as Supplementary Material).

\subsection{Comparative growth studies}

To determine the potential impact of the eastern Ecuador pathotype of $P$. spegazzinii on the growth of $M$. micrantha, a series of comparative growth experiments using a single inoculation were conducted under three different conditions: (a) in the quarantine screenhouse; (b) in open sunlight and (c) under cocoa trees. These three experiments were not conducted simultaneously.

For each experiment, 150 cuttings of mature $M$. micrantha stems of approximate equal length ( $\mathrm{ca} 10 \mathrm{~cm}$ ) and possessing at least one node, were collected from the field and propagated by planting single stem pieces, with the node exposed, in plastic drinking cups (70 $\mathrm{mm}$ diameter $\times 85 \mathrm{~mm}$ high) filled with steam-sterilized topsoil. Plants were grown to the 4-5 leaf stage in the quarantine screenhouse, usually about 3-4 weeks after planting. All side shoots were removed, so only one actively growing stem remained on each plant.

For the quarantine 'screenhouse' experiment, 10 similar-sized plants were assigned randomly to each of four treatments: single stem inoculated (SSI), single stem control (SSC), multi-stem inoculated (MSI) and multi-stem control (MSC). An additional 10 plants were used to obtain initial dry weights to confirm uniformity of the plants. For the 'open-sunlight' and 'under-cocoa-trees' experiments, 20 plants were used in each of the four treatments and to obtain initial dry weights.

All test plants were inoculated by placing the plants under a raised wire mesh platform supporting 10-15 small, heavily rustinfected plants, containing mature pustules in the inoculation chamber in the quarantine laboratory. The fresh clean plants were positioned under the infected plants such that released spores could fall onto the young shoots of the clean plants below. Inoculated plants were removed from the inoculation chamber after $48 \mathrm{~h}$ and kept on a bench under a light bank in the quarantine laboratory for two days before being placed in the quarantine screenhouse, as already described. For the quarantine screenhouse experiment, the height of each plant was measured and the number of nodes on the main stem recorded. Inoculated and control pots were placed in their respective groups, about $1 \mathrm{~m}$ apart in the quarantine screenhouse to minimise the chance of the control plants becoming infected.

For the open-sunlight and under-cocoa-trees experiments, all plants were transplanted into larger pots $(200 \mathrm{~mm}$ diameter $\times 180 \mathrm{~mm}$ high), one week following inoculation. The height 
and the number of nodespresent on each plant were recorded prior to plants being placed out in the field. Plants in the open-sunlight experiment were placed out in the open, away from trees and buildings, while plants in the under-cocoa-trees experiment were placed in an area shaded by cocoa trees.

For both the open-sunlight and under-cocoa-trees experiments, wooden stakes $1 \mathrm{~m}$ long were placed in pots as supports to allow plants to grow upright. Inoculated pots were placed $3 \mathrm{~m}$ from the control plants to minimise the chance of the control plants becoming infected. An insecticide application of Karate ${ }^{\circledR}$ (Lambda-cyhalothrin) $0.5 \mathrm{~mL}: 500 \mathrm{~mL}$ of water mixed in a hand-held sprayer was applied to the young developing leaves and growing tips to control thrips after weekly measurements were taken. A buffer zone around the study site was also sprayed with Karate ${ }^{\circledR}$ and maintained for the duration of the experiment.

For all three experiments, the height and number of nodes were recorded weekly. Developing side shoots on the single-stemmed plants were removed, while those on the multi-stemmed plants were allowed to develop (and counted each week) to determine whether rust infection influences the development of side shoots. The total number of infected leaves, petioles and stems, and the total number of pustules on each inoculated plant were recorded weekly.

The experiments continued for five weeks, allowing one generation of the rust to be completed on the plants, upon which all surviving plants were carefully uprooted. Roots were washed thoroughly under running tap water to remove all soil. Each plant was separated into leaves, stems and roots, which were placed in individual paper bags in an oven (Labec Equipment Pty Ltd, temperature controller) and dried at $60^{\circ} \mathrm{C}$ for three days, after which they were weighed separately, using an electronic balance (Sartorius BP 2100 S, Biolab Scientific Ltd).

\subsection{Data analysis}

Growth rates, the number of new nodes and dry weights of inoculated and control plants were compared using a two-way ANOVA, with stem density (single vs multi-stem) and treatment (inoculated $v s$ control) as factors in the screenhouse experiment and a three-way ANOVA (with stem density, treatment and site (open sunlight and under cocoa trees) in the open-sunlight and under-cocoa-trees experiments. Secondary stem data were analysed using a one-way ANOVA for the screenhouse experiment and analysed using a two-way ANOVA for the open-sunlight and under-cocoa-trees experiments. Differences among means were examined using Fisher's LSD test. Correlations between the number of pustules and (a) growth rate, (b) the number of new nodes and (c) final dry weight were examined. Simple linear regressions were conducted to determine the best model to describe the relationship between the number of pustules and (a) growth rate, (b) the number of new nodes and (c) final total dry weight.

\section{Results}

\subsection{Rust pathotype selection}

There was substantial variation in the aggressiveness of the different rust isolates towards the different $M$. micrantha accessions tested from Fiji and PNG. The rust pathotype from eastern Ecuador was the most aggressive, scoring 4+ for all but one of the plant accessions tested. The rust pathotypes from Trinidad and Costa Rica also rated highly and so can be considered suitable for PNG and Fiji. However, the pathotypes from Argentina, Peru, Brazil and western Ecuador were not considered for release in Fiji and
PNG, because at least one population of $M$. micrantha tested received a score of less than 4 (including $4-$ ) (Table 1 ).

\subsection{Host-specificity screening}

None of the 11 plant species tested became visibly diseased with $P$. spegazzinii, or showed any reaction to the inoculation with the rust basidiospores. The $M$. micrantha control plants included in each test run always expressed a fully compatible reaction to the rust fungus (see Table 2, Supplementary Material).

\subsection{Culturing techniques and pathogen development in PNG}

Telia continued to develop on the original plants sent from CABI over the seven days the plants were held in the inoculation chamber. By day 7, all pustules on the original plants had matured and sporulated, infecting a total of 23 plants.

The first visual symptoms of infection are chlorotic spots (mean diameter: $1.3 \pm 0.1 \mathrm{~mm} ; n=60$ ) on the underside of leaves, usually 7-10 days after inoculation. The spots enlarge into telia (mean diameter: $2.6 \pm 0.1 \mathrm{~mm} ; n=60$ ), which are bright yellow and appear after 13-16 days. The teliospores begin to mature, as evidenced by dark brown spots on the raised sori (mean diameter: $3.8 \pm 0.10 \mathrm{~mm} ; n=60$ ) after $18-22$ days, after which time they are ready to form basidiospores if conditions are suitable.

The most effective culturing method was when 3-4 week old cuttings were placed in the inoculation chamber with infected plants situated above. Using this method, all inoculated plants became infected (see Table 3 in Supplementary Material).

\subsection{Comparative growth studies}

Pustules developed normally on the inoculated plants and there was no cross-contamination of the control plants. However, the short duration of the experiment did not allow for the development of secondary infection on the test plants.

\subsection{Quarantine screenhouse experiment}

All inoculated plants developed pustules, with an average ( \pm standard error) of $28.8 \pm 9.0$ pustules/plant for single-stemmed plants $(n=10)$ and $50.0 \pm 18.0$ for multi-stemmed plants $(n=10)$. Inoculated plants had significantly lower mean growth rates than the uninfected plants $\left(F_{1,37}=13.57, p<0.001\right)$ (Fig. 1$)$. There was no interaction between stem density and infection rate $\left(F_{1,36}=0.58, p=0.451\right)$ and there was no correlation between the number of pustules and the growth rate of single- $(r=0.415$, $p=0.234)$ and multi-stemmed plants $(r=-0.090, p=0.804)$.

Inoculated plants had significantly fewer new nodes than uninfected plants $\left(F_{1,37}=8.39, p=0.006\right)$ (Fig. 2$)$. There was no interaction between stem density and infection rate $\left(F_{1,36}=0.15\right.$, $p=0.697)$ and there was no correlation between the number of pustules and the number of new nodes of single- $(r=0.462$, $p=0.178)$ and multi-stemmed plants $(r=0.457, p=0.184)$.

Inoculated plants had a significantly smaller final total dry weight than uninfected plants $\left(F_{1,37}=31.04, p<0.001\right)$ (Fig. 3$)$, so separate analyses of leaf, stem and dry weights were not conducted. There was no interaction between stem density and treatment $\left(F_{1,36}=0.01, p=0.926\right)$ and there was no correlation between the number of pustules and the final total dry weight of single$(r=0.266, p=0.458)$ and multi-stemmed plants $(r=0.188$, $p=0.604$ ) or the dry weights for leaves, stems and roots.

There was no difference in the number of secondary stems produced between inoculated and uninfected multi-stemmed plants $\left(F_{1,18}=0.00, p=1.00\right)$. 
Table 1

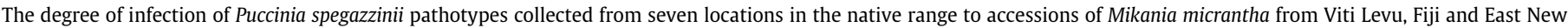

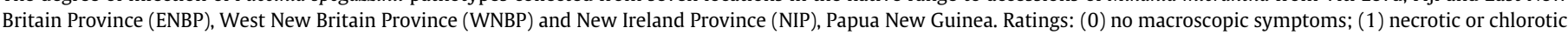

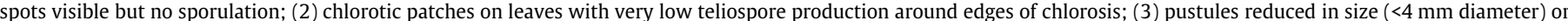

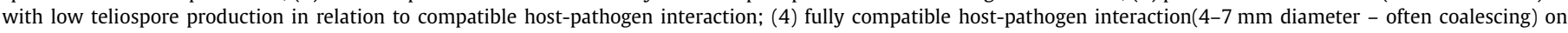

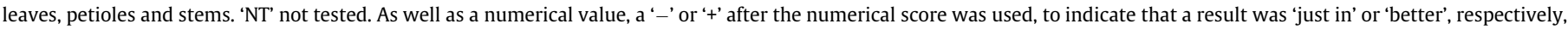
than the allocated numerical value.

\begin{tabular}{|c|c|c|c|c|c|c|c|}
\hline \multirow[t]{2}{*}{ M. micrantha accession } & \multicolumn{7}{|c|}{ Origin of Puccinia spegazzinii pathotype (IMI number) } \\
\hline & $\begin{array}{l}\text { Argentina } \\
(393078)\end{array}$ & $\begin{array}{l}\text { Peru } \\
(393076)\end{array}$ & $\begin{array}{l}\text { Brazil } \\
(393061)\end{array}$ & $\begin{array}{l}\text { Eastern Ecuador } \\
(393075)\end{array}$ & $\begin{array}{l}\text { Western Ecuador } \\
(393074)\end{array}$ & $\begin{array}{l}\text { Trinidad } \\
(393067)\end{array}$ & $\begin{array}{l}\text { Costa Rica } \\
(393069)\end{array}$ \\
\hline Naidascri, Fiji & 4 & $4-$ & NT & $4+$ & 4 & 4 & $4+$ \\
\hline Nausori, Fiji & 4 & 4 & 4 & $4+$ & $4+$ & 4 & 4 \\
\hline Koronivia, Fiji & $4-$ & 3 & 1 & $4+$ & 4 & 4 & $4+$ \\
\hline Varoka, Fiji & $4+$ & 4 & $3-$ & $4+$ & $4-$ & 4 & 4 \\
\hline Waibau, Fiji & $4-$ & $4-$ & 4 & $4+$ & 4 & 4 & NT \\
\hline $\begin{array}{l}\text { GazellePeninsula, ENBP, } \\
\text { PNG }\end{array}$ & 4 & $4+$ & 4 & 4 & 4 & 4 & 4 \\
\hline Kerevat, ENBP, PNG & 4 & $4+$ & 3 & $4+$ & 4 & 4 & 4 \\
\hline $\begin{array}{l}\text { Napapar } 4 \text { Village, ENBP, } \\
\text { PNG }\end{array}$ & 4 & 4 & 3 & $4+$ & 4 & 4 & 4 \\
\hline Central, WNBP, PNG & 4 & NT & NT & $4+$ & NT & NT & NT \\
\hline Kavieng, NIP, PNG & 4 & NT & NT & $4+$ & NT & NT & NT \\
\hline
\end{tabular}

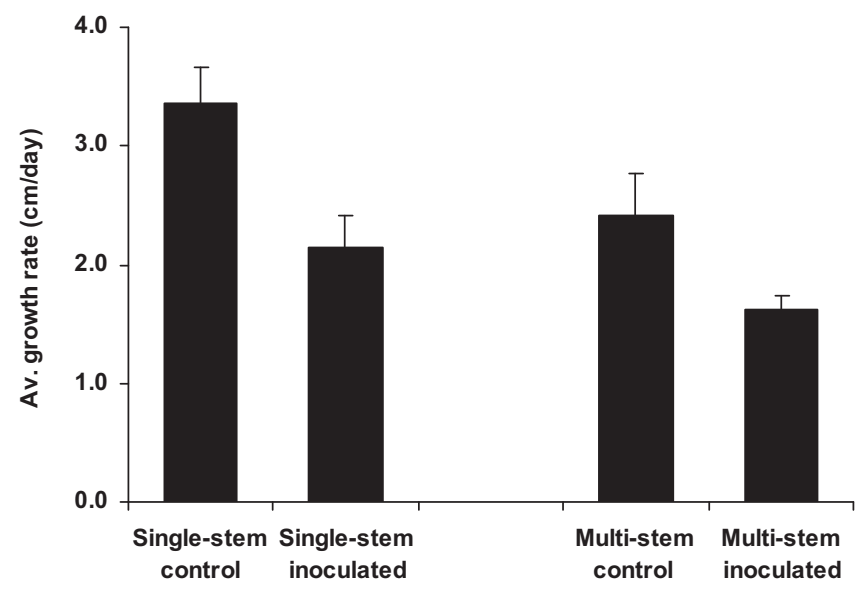

Fig. 1. The average growth rate ( \pm s.e.) over five weeks of single- and multistemmed M. micrantha plants inoculated with $P$. spegazzinii and of single- and multi-stemmed non-inoculated plants grown in a quarantine screenhouse with ambient temperature (ranging $28-40^{\circ} \mathrm{C}$ ).

\subsection{Open-sunlight and under-cocoa-trees experiments}

All inoculated plants in the open sun trial developed pustules, with an average ( \pm standard error) of $79.8 \pm 14.4$ pustules/plant for single-stemmed plants $(n=20)$ and $80.5 \pm 10.0$ for multistemmed plants $(n=19)$. However, one plant in the multistemmed trial died during the experiment.

All inoculated plants in the coca block trial developed pustules, with an average ( \pm standard error) of $20.4 \pm 4.3$ pustules/plant for single-stemmed plants $(n=18)$ and $43.4 \pm 16.8$ for multi-stemmed plants $(n=15)$. However, two plants in the single-stemmed trial and five plants in the multi-stemmed trial died during the experiment.

There was a significant interaction between sites, stem number and inoculation status in the growth rate of plants $\left(F_{1,131}=9.13\right.$, $p=0.003$ ) (Fig. 4). Single-stemmed inoculated plants placed in open sunlight had a significantly lower growth rate than uninfected plants placed in open sunlight. In addition, multi-stemmed inoculated plants placed under cocoa trees had a significantly lower growth rate than uninfected plants placed under cocoa trees. However, there was no difference in the growth rates of single-

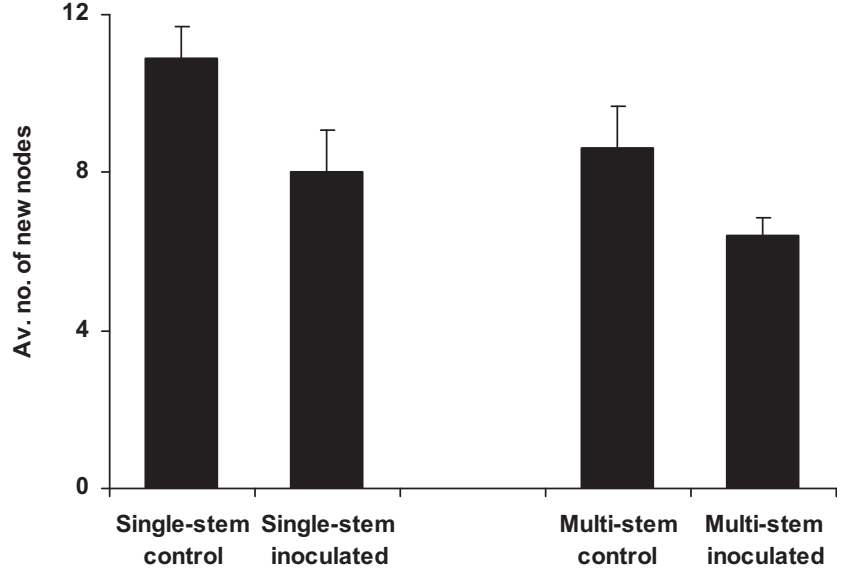

Fig. 2. The average number ( \pm s.e.) of new nodes formed over five weeks on singleand multi-stemmed $M$. micrantha plants inoculated with $P$. spegazzinii and on single- and multi-stemmed non-inoculated plants grown in a quarantine screenhouse with ambient temperature (ranging $28-40{ }^{\circ} \mathrm{C}$ )

stemmed inoculated plants and control plants placed under cocoa trees. Nor was there any difference in the growth rates of multistemmed inoculated plants and control plants placed in open sunlight.

There was a significant correlation between the number of pustules and growth rate of single-stemmed plants placed in open sunlight $(r=-0.517, p=0.020)$ but not between the number of pustules and growth rate of multi-stemmed plants placed in open sunlight $(r=-0.360, p=0.143)$. In addition, inoculated singlestemmed plants in open sunlight had a significantly lower growth rate than inoculated multi-stemmed plants $\left(F_{2,35}=12.29\right.$, $p<0.001$ ) (Fig. 5).

There was no correlation between the number of pustules and growth rate with respect to single- $(r=-0.343, p=0.163)$ and multi-stemmed plants $(r=-480, p=0.070)$ placed under cocoatrees. There was also no significant difference in the growth rate of inoculated single- and multi-stemmed plants placed under cocoa trees $\left(F_{2,30}=2.09, p=0.141\right)$. However, there was a marginally significant regression when groups (single- and multi-stemmed) were ignored $\left(R^{2}=9.1, p=0.049\right)$ (Fig. 6). 


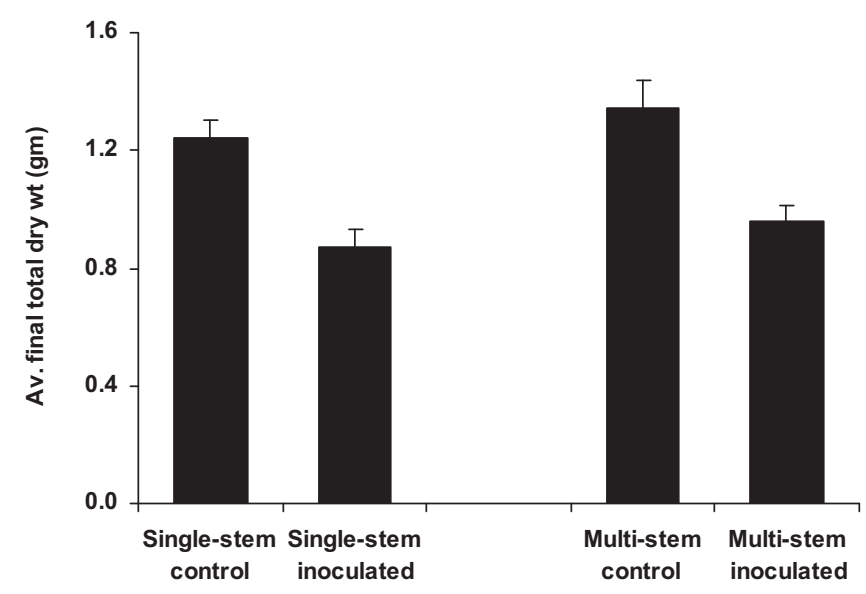

Fig. 3. The average final total dry weight ( \pm s.e.) after five weeks of single- and multi-stemmed $M$. micrantha plants inoculated with $P$. spegazzinii and of single- and multi-stemmed non-inoculated plants grown in a quarantine screenhouse with ambient temperature (ranging $28-40{ }^{\circ} \mathrm{C}$ ).

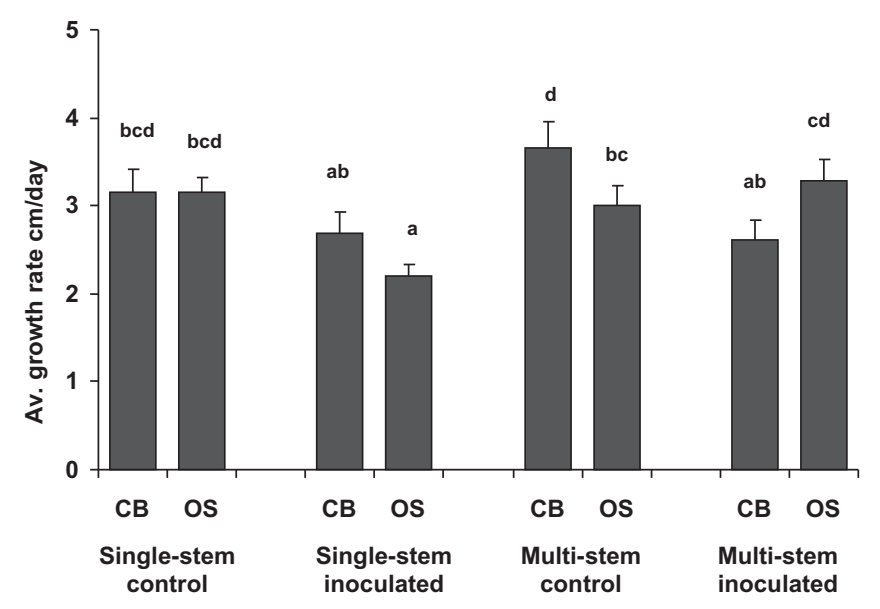

Fig. 4. The average growth rate ( \pm s.e.) over five weeks of single- and multistemmed $M$. micrantha plants inoculated with $P$. spegazzinii and of single- and multi-stemmed non-inoculated plants when grown in open sunlight (OS) and under cocoa trees $(\mathrm{CB})$. Growth rates with the same letter are not significantly different, using a Fisher's LSD test.

There was a significant interaction between sites, stem number and whether or not plants had been inoculated in the number of new nodes produced by plants $\left(F_{1,131}=6.59, p=0.011\right)$ (Fig. 7$)$. Single-stemmed inoculated plants placed in open sunlight produced significantly fewer new nodes than uninfected plants in open sunlight. In addition, multi-stemmed inoculated plants placed under cocoa trees produced significantly fewer new nodes than uninfected plants placed under cocoa trees. However, there was no difference in the number of new nodes of single-stemmed inoculated plants and control plants placed under cocoa trees. Nor was there any difference in the number of new nodes produced by multi-stemmed inoculated plants and control plants placed in open sunlight.

There was a significant correlation between the number of pustules and the number of new nodes produced by singlestemmed plants placed in open sunlight $(r=-0.496, p=0.026)$ but not between the number of pustules and the number of new nodes produced by multi-stemmed plants placed in open sunlight $(r=-0.415, p=0.087)$ (Fig. 8). In addition, inoculated singlestemmed plants in open sunlight had a significantly fewer new nodes than inoculated multi-stemmed plants $\left(F_{2,35}=8.66\right.$, $p<0.001$ ).
There was a significant correlation between the number of pustules and the number of new nodes produced by multi-stemmed plants placed under cocoa trees $\left(r=-0.523, F_{1,31}=0.045\right)$ but not between single-stemmed plants placed under cocoa trees $(r=-0.219, p=0.383$ ) (Fig. 9). There was also no significant difference in the number of new nodes of inoculated single- and multistemmed plants placed under cocoa trees $\left(F_{2,30}=2.62, p=0.089\right)$. However, there was a significant regression when groups (singleand multi-stemmed) were ignored $\left(R^{2}=11.0, p=0.034\right)$ (Fig. 9).

There was a significant interaction between sites, stem number and whether or not plants had been inoculated in the final total dry weight of plants $\left(F_{1,130}=12.93, p<0.001\right)$ (Fig. 10). Singlestemmed inoculated plants placed in open sunlight had a significantly smaller final total dry weight than uninfected plants in open sunlight. However, there was no difference in the final total dry weight of multi-stemmed inoculated plants and control plants placed under cocoa trees, single-stemmed inoculated plants and control plants grown under cocoa trees and multi-stemmed inoculated plants and control plants grown in open sunlight.

There was a significant correlation between the number of pustules and the final total dry weight of single-stemmed plants placed in open sunlight $(r=-0.531, p=0.016)$ but not between the number of pustules and final total dry weight for multi-stemmed plants placed in open sunlight $(r=-0.121$, $p=0.632$ ). In addition, inoculatedsingle-stemmed plants in open sunlight had a significantly smaller final dry weight than inoculated multi-stemmed plants $\left(F_{2,35}=18.71, p<0.001\right)$ (Fig. 11). There was also a significant correlation between the number of pustules and the final dry weight of leaves $(r=-0.55, p=0.012)$ and roots $(r=-0.443, p=0.050)$ of single-stemmed plants placed in open sunlight when leaves, stems and roots were analysed separately.

There was no significant correlation between the number of pustules and final total dry weight with respect to single$(r=-0.266, p=0.286)$ and multi-stemmed plants $(r=-0.330$, $p=0.229$ ) placed under cocoa-trees. There was also no significant difference in the final total dry weight of inoculated single- and multi-stemmed plants placed under cocoa trees $\left(F_{2,30}=1.77\right.$, $p=0.188$ ) or when the regression was analysed with groups (single- and multi-stemmed) ignored $\left(R^{2}=2.0, p=0.207\right)$.

There was no difference in the number of secondary stems produced between the inoculated and control multi-stemmed plants $\left(F_{1,63}=1.65, p=0.204\right)$ and the interaction between stem density and treatment was not significant $\left(F_{1,62}=2.32, p=0.133\right)$.

\section{Discussion}

P. spegazzinii from eastern Ecuador was the most effective pathotype against $M$. micrantha present in both PNG and Fiji and it is likely that, due to the movement of people in the Pacific and the way $M$. micrantha has spread in the region, this pathotype will also be the most effective for other countries in the Pacific. Pathogenicity testing showed that $M$. micrantha accessions from different countries have differing susceptibilities to different pathotypes of P. spegazzinii (Ellison et al., 2004). This suggests that M. micrantha was probably introduced to some countries or regions independently and probably from different areas within its native range. In India, M. micrantha was thought to have been introduced twice, once in the early 1900s (Choudhury, 1972) and again during World War II (Puzari et al., 2010). Pathogenicity testing showed that there were differences in the rust susceptibility of M. micrantha found in different parts of India, with M. micrantha in Assam being most susceptible to the pathotype from Peru and M. micrantha in Kerala being most susceptible to the pathotype from Trinidad (Ellison et al., 2004; Ellison et al., 2007). 


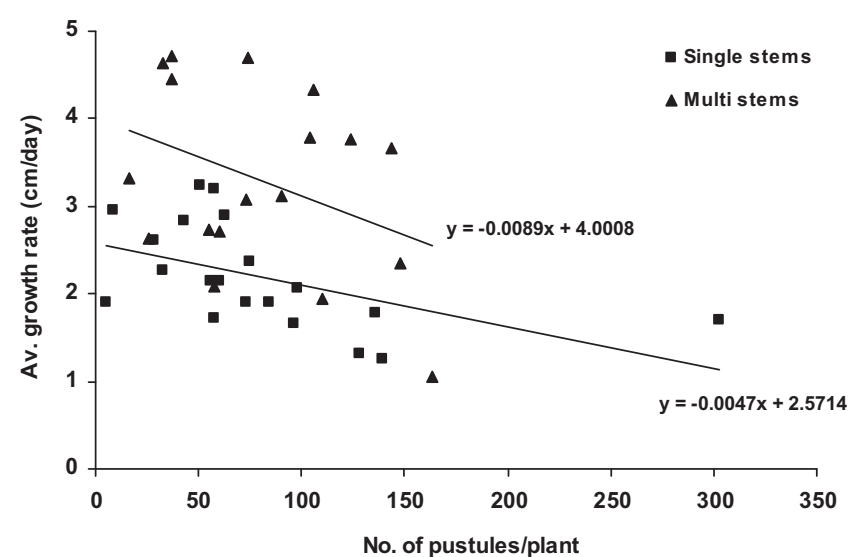

Fig. 5. The relationship between the number of pustules of $P$. spegazzinii present on $M$. micrantha and the growth rate over five weeks of single- and multi-stemmed plants grown in open sunlight.

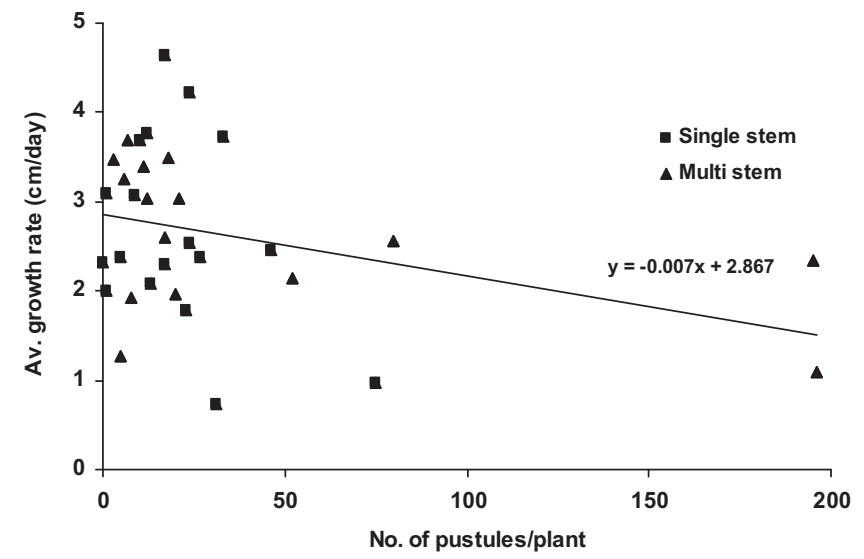

Fig. 6. The relationship between the number of pustules of $P$. spegazzinii present on M. micrantha and the growth rate over five weeks of single- and multi-stemmed plants grown under cocoa trees.

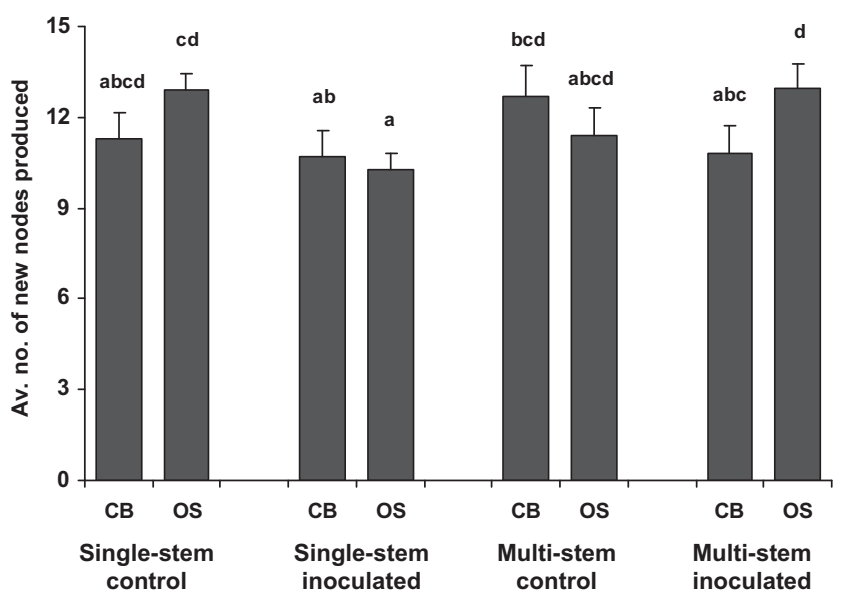

Fig. 7. The average number ( \pm s.e.) of new nodes produced after five weeks on single- and multi-stemmed M. micrantha plants inoculated with $P$. spegazzinii and on single- and multi-stemmed non-inoculated plants when grown in open sunlight $(\mathrm{OS})$ and under cocoa trees (CB). Numbers of new nodes with the same letter are not significantly different, using a Fisher's LSD test.

The east Ecuadorian pathotype of the rust was extensively screened before being released in Taiwan in 2008 and the host specificity results here confirmed the pathotype to be specific to

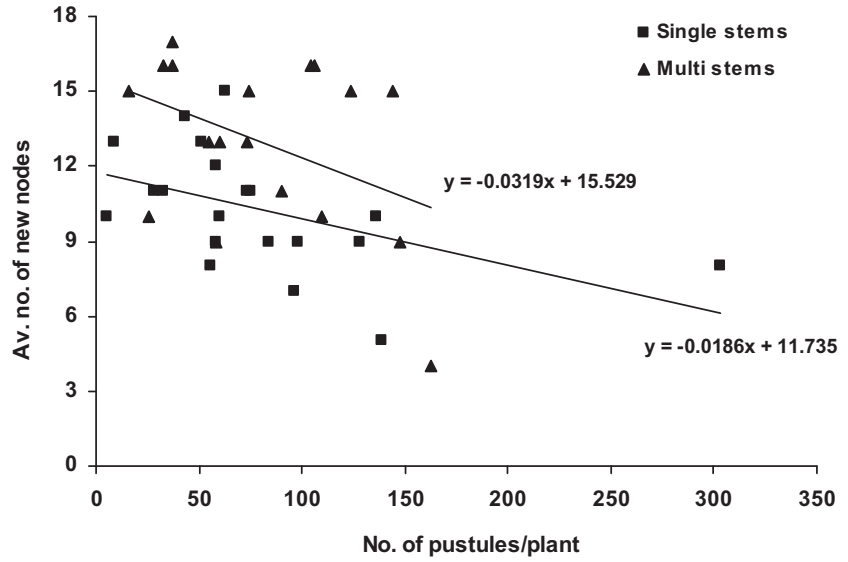

Fig. 8. The relationship between the number of pustules of $P$. spegazzinii present on $M$. micrantha and the number of new nodes produced after five weeks by singleand multi-stemmed plants grown in open sunlight.

the genus Mikania, in common with all the pathotypes of this species that have been tested. The additional host specificity testing prior to release in the Pacific region focused on the interaction of the pathotype from eastern Ecuador with a selected number of important, or taxonomically-relevant plants (e.g. Zinnia and B. pilosa, which are in the same family as M. micrantha) from the Pacific.

Earlier testing confirmed the rust is able to infect $M$. cordata, which is native to, and found throughout Southeast Asia and parts of PNG (Holmes, 1982; Ellison et al., 2008). However, M. cordata is generally found in high altitude or cool areas while $M$. micrantha is found in lowland areas below $1100 \mathrm{~m}$ (Day et al., 2012). Following the submission of a dossier outlining the biology and host specificity testing of $P$. spegazzinii to the authorities in PNG, the rust was approved for field release. The rust was introduced into PNG in November 2008 and was cultured through one generation in quarantine prior to being field released.

Culturing methods trialled showed that plants suitable for inoculation can be easily grown in small plastic drinking cups which are readily available in PNG and many other countries. Infection was easily attained using young plants with actively growing tips, if humidity was sufficiently high to evoke the production and release of basidiospores and if there was free water on the inoculated plants for adequate time $(>10 \mathrm{~h}$ ) for infection. The success in using a simple, sealed inoculation chamber made from Perspex means that other countries, which do not have access to elaborate equipment, could easily culture the rust if required. In addition, achieving successful infection of plants in the shadehouse under natural conditions suggested that field inoculations and natural spread of the rust should be possible in PNG and other countries once the rust establishes in the field.

The comparative growth trials showed that $P$. spegazzinii can reduce the growth of $M$. micrantha, with growth rates of inoculated plants significantly lower than control plants. There were significant correlations between the number of pustules and (a) growth rate, (b) the number of new nodes and (c) final total dry weight of single-stemmed plants placed in open sunlight, as well as between the number of pustules and the number of new nodes of multi-stemmed plants placed under cocoa trees. However, in these experiments, fewer than 10 pustules were seen on some plants which suggest that even with low levels of infection, $P$. spegazzinii can have a negative impact on $M$. micrantha.

While these results are encouraging, these experiments looked at the impact of the number of pustules per plant resulting from only a single inoculation on the growth of 3-4 week old plants. Secondary infection of the inoculated plants was not observed in 


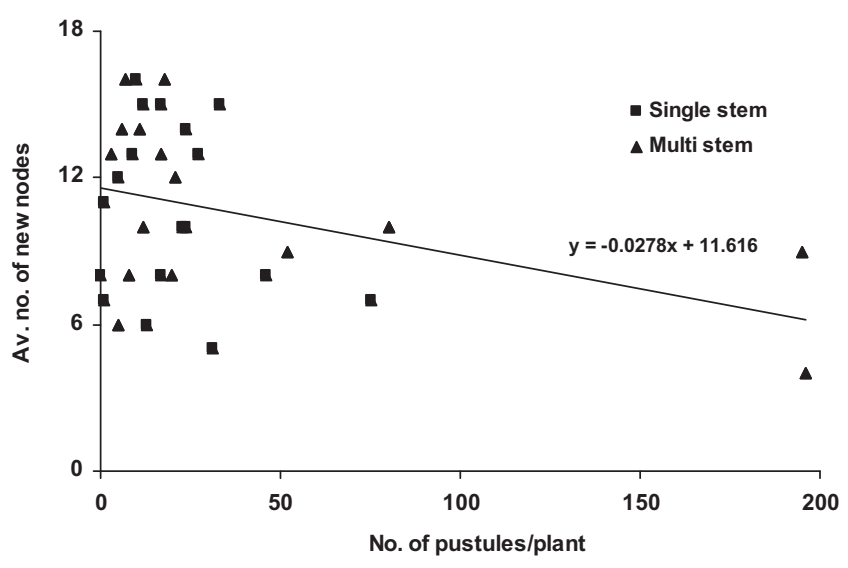

Fig. 9. The relationship between the number of pustules of $P$. spegazzinii present on M. micrantha and the number of new nodes produced after five weeks by singleand multi-stemmed plants grown under cocoa trees.

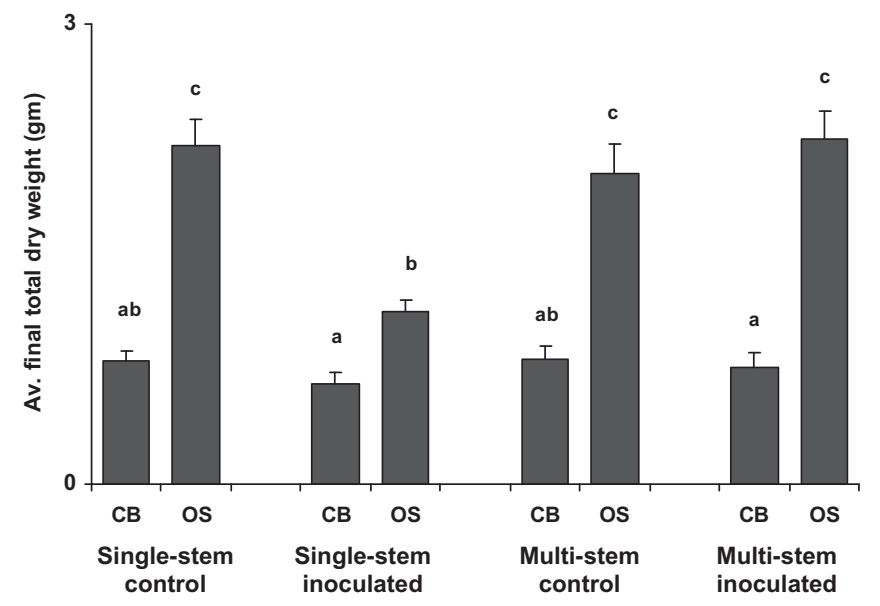

Fig. 10. The average final total dry weight ( \pm s.e.) after five weeks of single- and multi-stemmed $M$. micrantha plants inoculated with $P$. spegazzinii and of single- and multi-stemmed non-inoculated plants when grown in open sunlight (OS) and under cocoa trees (CB). Dry weights with the same letter are not significantly different, using a Fisher's LSD test.

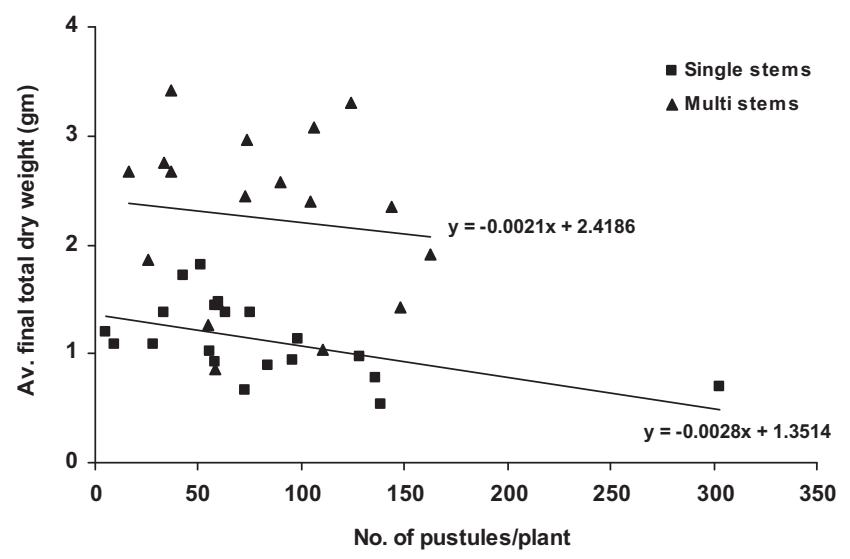

Fig. 11. The relationship between the number of pustules of $P$. spegazzinii present on $M$. micrantha and the total dry weight after five weeks of single- and multistemmed plants grown in open sunlight.

the present work and it is likely that prevailing conditions and the short (five weeks) duration of the experiments were contributing factors.
In the natural field situations, the age and size of $M$. micrantha plants are likely to be greater and secondary infection will occur, as established plants should receive repeated infections from surrounding infected plants over time. This will result in higher pustule density and longer infection periods than plants experienced in these experiments. Therefore, it is expected that damage to $M$. micrantha by $P$. spegazzinii in the field to be greater than seen here. Thus, $P$. spegazzinii has the potential to reduce the density of $M$. micrantha, benefitting farmers through reduced weed control and increasing food security through reduced crop losses (Day et al., 2012).

The variable results achieved in the experiments conducted in open sunlight and under cocoa trees may be due to a number of factors, including greater environmental variation under field conditions. One such factor was damage arising from attack by other organisms. For example, a large number of shoot tips were damaged, possibly due to feeding by insects despite the application of pesticides. Nevertheless, P. spegazzinii has been released and has established in numerous sites throughout PNG. Field releases are continuing, with regular monitoring being conducted at selected sites to determine the impact of $P$. spegazzinii on $M$. micrantha.

\section{Acknowledgments}

The authors wish to acknowledge the assistance of Kiteni Kurika, John Bokosou, Mundon Binifa, all of NARI and Jenitha Fidelis, PNGCCI for technical assistance. We are also gratefulto Drs H.C. Evans, F.D. Panetta, A.R. Pople, J.C. Scanlan and W.A. Palmer for helpful comments on the manuscript and Kerri Dawson for advice on the analyses. This project was funded by the Australian Centre for International Agricultural Research and the Secretariat of the Pacific Community. The rust is held in the UK under DEFRA licence no. PHL $182 / 4869$.

\section{Appendix A. Supplementary data}

Supplementary data associated with this article can be found, in the online version, at http://dx.doi.org/10.1016/j.biocontrol.2013. 08.007 .

\section{References}

Choudhury, A., 1972. Controversial Mikania (climber) - a threat to the forests and agriculture. Indian Forester 98, 178-186.

Cock, M.J.W., Ellison, C.A., Evans, H.C., Ooi, P.A.C., 2000. Can failure be turned into success for biological control of mile-a-minute weed (Mikania micrantha)? In: Spencer, N.R. (Ed.), Proceedings of the X International Symposium on Biological Control of Weeds. USDA Agricultural Research Service, Bozeman, Montana, USA, pp. 155-167.

Day, M.D., Kawi, A., Tunabuna, A., Fidelis, J., Swamy, B., Ratutuni, J., Saul-Maora, J., Dewhurst, C.F., Orapa, W., 2011. The distribution and socio-economic impacts of Mikania micrantha (Asteraceae) in Papua New Guinea and Fiji and prospects for its biocontrol. In: McFadyen, R., Chandrasena, N., Adkins, S., Hashem, A., Walker S., Lemerle, D., Weston, L., Lloyd, S. (Eds.), Proceedings of the 23rd Asian-Pacific Weed Science Society Conference. Asian-Pacific Weed Science Society. Cairns, Australia, pp. 146-153.

Day, M.D., Kawi, A., Kurika, K., Dewhurst, C.F., Waisale, S., Saul-Maora, J., Fidelis, J., Bokosou, J., Moxon, J., Orapa, W., Senaratne, K.A.D., 2012. Mikania micrantha Kunth (Asteraceae) (mile-a-minute): Its distribution and physical and socioeconomic impacts in Papua New Guinea. Pac. Sci. 66, 213-223.

Desmier de Chenon, R., Sipayung, A., Sudharto, P., 2002. A new biological agent, Actinote anteas, introduced into Indonesia from South America for the control of Chromolaena odorata. In: Zachariades, C., Muniappan, R., Strathie, L.W. (Eds.), Proceedings of the Fifth International Workshop on Biological Control and Management of Chromolaena odorata. ARC-PPRI, Durban, pp. 170-176.

Ellison, C., Day, M., 2011. Current status of releases of Puccinia spegazzinii for Mikania micrantha control. Biocontrol News Info. 32, 1N.

Ellison, C.A., Evans, H.C., Ineson, J., 2004. The significance of intraspecies pathogenicity in the selection of a rust pathotype for the classical biological control of Mikania micrantha (mile-a-minute weed) in Southeast Asia. In: Cullen, J.M., Briese, D.T., Kriticos, D.J., Lonsdale, W.M., Morin, L., Scott, J.K. (Eds.), 
Proceedings of the XI International Symposium on Biological Control of Weeds. CSIRO Entomology, Canberra, Australia, pp. 102-107.

Ellison, C.A., Puzari, K.C., Kumar, P.S., Dev, U., Sankaran, K.V., Rabindra, R.J. Murphy, S.T., 2007. Sustainable control of Mikania micrantha implementing a classical biological control strategy in India using the rust fungus Puccinia spegazzinii. In: Lai, P.-Y., Reddy, G.V.P., Muniappan, R. (Eds.), Proceedings of the Seventh International Workshop on Biological Control and Management of Chromolaena odorata and Mikania micrantha. National Pingtung University of Science and Technology, Pingtung University, Taiwan, pp. 94-105.

Ellison, C.A., Evans, H.C., Djeddour, D.H., Thomas, S.E., 2008. Biology and host range of the rust fungus Puccinia spegazzinii: a new classical biological control agen for the invasive, alien weed Mikania micrantha in Asia. Biol. Control 45, 133 145

Evans, H.C., Ellison, C.A., 2005. The biology and taxonomy of rust fungi associated with the neotropical vine Mikania micrantha, a major invasive weed in Asia. Mycologia 97, 935-947.

Holm, L.G., Plucknett, D.L., Pancho, J.V., Herberger, J.P., 1991. Mikania cordata (Burm. f.) B.L. Robinson, Mikania scandens (L.) Willd., and Mikania micrantha HBK. The world's worst weeds: distribution and biology. Krieger Publishing Company, Malabar, Florida, pp. 320-327.

Holmes, W.C., 1982. Revision of the old world Mikania (Compositae). Botanisches Jahres Beitraegefuer Systematik 103, 211-246.

Orapa, W. 2001. Impediments to increasing food security in PNG: the case of exotic weed species. In: Bourke, R.M., Allen, M.G., Salisbury, J.G. (Eds.), Food security for Papua New Guinea. Proceedings of the Papua New Guinea Food and Nutrition 2000 Conference. ACIAR, Lae, Papua New Guinea, pp. 308-315.

PIER - Pacific Island Ecosystems at Risk., 2012. Plant threats to Pacific Ecosystems. <http://www.hear.org/pier/scientificnames/index.html> (accessed 06.2012)

Puzari, K.C., Bhuyan, R.P., Pranab, D., Nath, H.K.D., 2010. Distribution of Mikania and its economic impact on tea ecosystem of Assam. Indian J. For. 33, 71-76.

Waterhouse, D.F., 1994. Biological Control of Weeds: Southeast Asian Prospects. ACIAR, Canberra.

Waterhouse, D.F., Norris, K.R., 1987. Biological Control: Pacific Prospects. Inkata Press, Melbourne.

Wirjahardja, S., 1976. Autecological study of Mikania spp. Proceedings of 5th AsianPacific Weed Science Society Conference. Asian-Pacific Weed Science Society, Tokyo, Japan, pp. 70-73. 